\title{
Alarma sobre el aplastamiento de la persona en la sociedad contemporánea: José Jiménez Lozano en la prensa regional (2005-2007)
}

\section{Risk of Human Devastation in Modern Society: José Jiménez Lozano in the Regional Press (2005-2007)}

María Merino Bobillo. Universidad de Valladolid

Recibido: 25-I-2011 - Aceptado: 3-VII-2011

Resumen:

Las enfermedades de la sociedad contemporánea son descritas, con lucidez y brillantez literaria, por el periodista y escritor José Jiménez Lozano, en las entregas periodísticas al Grupo Promecal. Los nacionalismos, la movida y el botellón, la violencia de género, el lenguaje sexista, etc. son retazos de la actualidad que su mirada atraviesa y dimensiona. Sus artículos traspasan la contingencia de lo periodístico para convertirse en propuestas culturales con tonalidad universal. No se quedan en la crítica de los sucesos concretos sino que, apoyándose en ellos, derivan en reflexiones de corte antropológico y ofrecen pensamientos válidos para los lectores de hoy y de mañana.

Palabras clave:

José Jiménez Lozano, sociedad contemporánea, periodismo de opinión, humanismo.

Abstract:

Society's illnesses are described with literary brilliancy by the journalist and writer Jose Jiménez Lozano in the Promecal Group's issue. The nationalisms, gender violence, sexist language Etc. these are some of the challenges which he goes through and pierces with his eye. His articles go beyond journalistic eventualities and turn into cultural and universal propositions.

Keywords:

José Jiménez Lozano, Modern Society, Interpretative Journalism, Humanism. 


\section{Introducción}

El objetivo del estudio ha sido conocer la temática de fondo que recorren los artículos que José Jiménez Lozano escribe en la actualidad. Proponemos como hipótesis el hecho de que estos traspasan la contingencia de lo periodístico para convertirse en propuestas culturales con tonalidad universal y que el contenido de esas propuestas lo constituye la alarma sobre la deshumanización de la sociedad y el aplastamiento sufrido por la persona.

Para ello analizamos los textos publicados entre los años 2005 y 2007 en la prensa regional que pertenece al Grupo Promecal. Citaremos en ocasiones a Osaca, una revista semanal del Grupo en la que durante una temporada se publicaban los artículos de Jiménez Lozano, y otras veces a El Día de Valladolid, cuando los artículos pasaron a publicarse en las ediciones de los periódicos. La metodología utilizada ha sido el análisis cualitativo del discurso mostrando especial interés en las referencias sociales y culturales implícitas y explícitas detectables en los artículos. Ello nos ha llevado a la selección de 36 artículos que responden a dicho enfoque y de los que incluiremos algunos fragmentos.

La hipótesis inicial arranca del primer artículo del autor en El Día de Valladolid en el que, sin que él lo declare de manera manifiesta, se descubre toda una declaración de intenciones. Comienza afirmando su intención de acercarse al conocimiento de las cosas tal como son y no deformadas por criterios exteriores a ellas mismas. Lo hace a través de la metáfora: la luz de la candela y la eléctrica. Para él, aquella se corresponde con el acercamiento natural a la realidad, algo que conoció en su infancia y que aplica a todo el campo del saber:

"Nos permitió, sin ir más lejos, ver y mirar a los hombres y las cosas como durantes siglos habían sido vistos [...] tal como habían sido hechos para ser vistos, es decir, a la luz del día o de una candela" (2005a).

En segundo lugar manifiesta su preocupación por la situación que se da en España:

“[...] el fantasma que vuelve a asediar a España. Como si en ella la historia no avanzase, sino que se enquistase y retornase luego. [...] Los tiempos decimonónicos de poner y arreglar, o quitar constituciones o del cantonalismo y ¡Viva Cartagena! Poniéndonos el mundo por montera, las escenas de las burlas religiosas más primarias, y los vivas a la libertad como en ciudad sin ley o anomia pura. ¿España como cabo de vela de una candelilla que se apaga, ahora de nuevo?" (2005a).

Así pues hemos intentado agrupar los artículos según respondan a alguno de esos criterios: a comentar la situación de la vida política en España o su comentario particular, sobre las cuestiones más sociales y culturales. Los primeros se reúnen en el epígrafe titulado "Síntomas de deterioro de la vida política en España” 
y los segundos en "Alarma sobre el aplastamiento sufrido por la persona y la deshumanización de la sociedad".

El nombre de José Jiménez Lozano se encuentra ligado al de su obra literaria, expresada en una amplia gama de géneros que van desde la novela a la poesía, al ensayo o la narración breve y que le ha hecho valedor de premios de prestigio: en 1988 el Premio Castilla y León de las Letras, en 1989 el Premio Nacional de la Crítica, en 1992 Premio Nacional de las Letras Españolas y en el 2002 el Premio Miguel de Cervantes.

Sus escritos vienen marcados por una personalidad forjada por la lectura asidua de una amplia literatura. Su modo de ver la vida -el despego de la técnica, del consumo, el sentimiento de la irrelevancia de la política- tiene mucho que ver con el hábitat rural en el que siempre ha vivido. Su profundo respeto de la vida, por las vivencias de la posguerra española.

El impacto de su pluma ha traspasado las fronteras españolas, viéndose traducida su obra en diez idiomas. La importancia de su escritura se muestra también en el interés que ha alcanzado en el ámbito académico y que se ha plasmado en la elaboración de tesis y tesinas, cinco de ellas fuera de España.

No ocurre lo mismo con su obra periodística, que hasta el momento ha pasado desapercibida. Sin embargo, periodismo y literatura surgen de la mano de la misma persona, por lo que no resulta extraña la investigación sobre la producción de ambas facetas de un autor. Desde mediados de los años cincuenta comenzó a colaborar con diversas publicaiones. A partir del año 2005 lo hace en los periódicos del Grupo Promecal. En ellos denuncia la tendencia a sobredimensionar el papel del Estado en las democracias, la intromisión en la vida del ciudadano, la falta de competencias profesionales de los políticos. Describe con lucidez y brillantez literaria las enfermedades de la sociedad contemporánea: los nacionalismos, la movida y el botellón, la violencia de género, el lenguaje sexista, etc., son retazos de la actualidad que su mirada atraviesa y dimensiona. Como se ha señalado, ofrece propuestas culturales con tonalidad universal. Queremos decir con ello que no se queda en la crítica de los sucesos concretos, sino que se apoya en ellos para derivar en reflexiones de corte antropológico que van más allá de la opinión periodística. Son universales, además, porque ofrecen pensamientos que resultan actuales no solo durante la lectura diaria del periódico, sino que trascienden la limitada temporalidad del diario y permanecen frescos cuando se leen tras el paso del tiempo. Su vigencia tiene también un carácter espacial, pues no se dirigen a los lectores de los periódicos locales o regionales que pertenecen a Promecal, sino a aquellos de ámbitos más remotos. Son universales tanto por su contenido como por la forma. En cuanto al primero porque el punto de arranque de sus textos, la actualidad, se queda difuminado por la reflexión general. En cuanto a la forma, por la ausencia total de referencias a nombres de políticos, por la escasa presencia de hechos 
circunstanciales y su sustitución por las referencias a hechos históricos, o de pensadores clásicos, o incluso de referencias al sentido común del pueblo.

Antes de acometer el estudio nos parece necesario explicar cómo llegó este autor al periodismo y cuál ha sido su recorrido en el mismo.

\section{Camino hacia el periodismo}

José Jiménez Lozano nació en 1930 en la provincia de Ávila, en un pueblo llamado Langa. En él pasó su infancia y adolescencia, salvo las ausencias obligadas por la continuación de los estudios de bachillerato que no era posible realizar en aquel pequeño lugar. Cuando tenía seis años estalló la Guerra Civil, es decir, que era un niño ajeno al mundo bipolar que vivían los mayores. Salvo porque la casa de sus padres se convirtió en un lugar de acogida de los que huían de un bando o de otro. Le llegaron los rumores y cuchicheos sobre depuraciones. La hospitalidad paterna y el ambiente de horror marcaron en él una personalidad profundamente inclinada al respeto a los demás, y muy especialmente inclinada a defender siempre a las víctimas, a los perseguidos, como queda patente y de modo constante, en su obra literaria.

La vida en el pueblo marcó en él una profunda huella, al crecer aprendiendo de la cercanía con la naturaleza y viviendo de cerca las luces y las sombras del trabajo en el campo. Nunca abandonó el medio rural, ni por los estudios universitarios, ni por la profesión periodística. En 1956 su padre fue trasladado a otro pueblo, esta vez a 35 kilómetros de Valladolid, Alcazarén, y allí permanece en la actualidad. En aquella ciudad estudió Derecho y posteriormente se instaló temporalmente en Madrid para preparar el examen de entrada en la carrera judicial. Sin embargo, el fracaso en uno de los exámenes le hizo recapacitar sobre su vocación profesional. Lo suyo no era ser juez. Por entonces había enviado algún artículo a El Norte de Castilla y su subdirector, Miguel Delibes, había apreciado la calidad de aquel texto, tanto por su contenido como por su expresión. En 1961 pasó a ser el director y ya desde su primer nombramiento emprendió diversas iniciativas, como la inauguración de secciones y la incorporación de jóvenes inquietos que, con el tiempo, se convirtieron en grandes figuras del periodismo, de la literatura o del pensamiento, como Manuel Leguineche, Francisco Umbral, César Alonso de los Ríos o Julián Marías. Entre ellos se encontraba José Jiménez Lozano. Cuando publicó su primer artículo en El Norte, tenía 26 años. Delibes reconoció que se hallaba frente a una persona de cualidades excepcionales, como testimonia sin ambages en diferentes ocasiones. Entre ambos nació una relación intensa y prolongada que se trasladó del registro profesional al de la amistad. El joven opositor abandonó su proyecto de convertirse en juez y siguió los cursos de la Escuela Oficial de Periodismo, que daban acceso a obtener el carné de periodista, requisito indispensable para ejercer la profesión. 
Las primeras colaboraciones aparecieron en "Las Artes y las Letras" donde fue escribiendo a lo largo de 13 años. En esas colaboraciones muestra unas características que permanecerán a través del tiempo: expresión seria y correcta, profundidad de los conocimientos, amplia cultura, juicio fino, actitud rebelde y una acusada personalidad.

A los tres años le ofreció cubrir la columna en la contraportada que, hasta entonces, era escrita por José Luis Martín Descalzo, sacerdote y escritor muy estimado en el mundo cultural vallisoletano, y que dejaba pues se trasladaba a Roma. Desde 1959 hasta 1965, se hizo cargo de la misma.

En 1961 Miguel Delibes puso en marcha un nuevo proyecto: el suplemento dominical "El Caballo de Troya". Para la nueva iniciativa contó con Jiménez Lozano, entonces con 31 años, como su pieza clave, como él mismo relata en una de sus obras:

“[...] fundé un día una sección de El Norte titulada 'El Caballo de Troya'. Esto de ‘El Caballo de Troya' era una cabeza de puente en el mundo de la frivolidad, dedicada a enseñar a pensar a los que ordinariamente no piensan y a tratar de ordenar el pensamiento de los que de buena fe desean pensar. La sección cayó muy bien; la sección llevaba el espíritu de Pepe Lozano que es, para entendernos, un espíritu de caridad justa. (Justa es una palabra incómoda pero insustituible, en este caso, para delimitar el concepto caridad, tan maltratado el pobre)" (Delibes, 1968: 118).

Las colaboraciones con el periódico se multiplicaban. Mientras mantenía la columna “Ciudad de Dios”, escribía en "Las Artes y las Letras” y capitaneaba “El Caballo de Troya”, el 27 de octubre de 1963 en la portada de El Norte de Castilla se anunciaba que José Jiménez Lozano viajaba a Roma para informar en directo de la celebración de la Segunda Sesión del Concilio Vaticano II. Residió dos meses en Roma y desde allí envió 16 largos textos en los que analizaba algunos de los documentos que se iban dando a conocer. Nuevamente fue requerido para ejercer esta tarea en las dos siguientes sesiones del Concilio, en 1964 y en 1965.

Todo esta escritura la compaginó con una nueva columna llamada "Mano Abierta", nombre con el que expresaba la franqueza de sus palabras. Solo duró un año su publicación y por la coincidencia temporal, seguramente la razón es que Miguel Delibes consiguió que Jiménez Lozano fuera ya contratado como redactor en plantilla. Era el año 1965. Su actividad en el periódico continuó con la redacción de artículos, reportajes, entrevistas, comentarios de la actualidad internacional y, desde el año 1973, con la elaboración de los editoriales. En 1978 fue nombrado subdirector y en 1992 se convirtió en el director hasta su jubilación en 1995. 
El prestigio de su pensamiento y de su escritura hizo que sus colaboraciones fueran requeridas por otros diarios y revistas. Con el fin de poder facilitar una visión global sobre su trayectoria en la prensa, ofrecemos la siguiente tabla en la que se recogen todas sus publicaciones.

\begin{tabular}{|c|c|c|}
\hline PUBLICACIÓN & FECHAS & TIPO DE TRABAJO \\
\hline \multicolumn{3}{|l|}{ PRENSA DIARIA } \\
\hline \multirow[t]{4}{*}{ El Norte de Castilla } & 1956 & Comienza colaboraciones \\
\hline & 1965 & Redactor \\
\hline & 1978 & Subdirector \\
\hline & $1992-1995$ & Director \\
\hline El Sol & 1991 & Colaboraciones \\
\hline El Pais & $1976-1985$ & Colaboraciones \\
\hline Informaciones & 1971-1978 & $\begin{array}{l}\text { Colaboraciones en "Las Firmas de } \\
\text { Informaciones" }\end{array}$ \\
\hline$A B C$ & $1993-2006$ & Terceras, otras colaboraciones \\
\hline La Razón & $\begin{array}{l}2007- \\
\text { actualidad }\end{array}$ & Columna \\
\hline \multicolumn{3}{|l|}{ REVISTAS } \\
\hline Destino & $1964-1980$ & $\begin{array}{l}\text { Cartas de un cristiano impaciente; Rojo y } \\
\text { Negro; Hombre y época }\end{array}$ \\
\hline Vida Nueva & 1971-1984 & Columna: "Bloc de Notas" \\
\hline $\begin{array}{l}\text { El Cisne } \\
\text { Questions de Vida } \\
\text { cristiana } \\
\text { Abrante } \\
\text { El Quijote } \\
\end{array}$ & & $\begin{array}{l}\text { Artículos } \\
\text { Artículos } \\
\text { Artículos } \\
\text { Artículos }\end{array}$ \\
\hline \multicolumn{3}{|c|}{ MEDIOS DIGITALES } \\
\hline $\begin{array}{l}\text { Centro Virtual } \\
\text { Cervantes }\end{array}$ & $1998-2002$ & Artículos \\
\hline \multicolumn{3}{|c|}{ GRUPOS DE COMUNICACIÓN } \\
\hline PROMECAL & $\begin{array}{l}2005- \\
\text { actualidad }\end{array}$ & Columna: "A la luz de una candela" \\
\hline
\end{tabular}

(Elaboración propia)

No deja de llamar la atención que, después de haber publicado en los grandes periódicos nacionales, la escritura de José Jiménez Lozano volviera a la prensa regional a partir del año 2005, en El Día de Valladolid, un diario que había nacido apenas cinco años antes bajo el patronazgo de El País. En el 2003, el periódico 
fue comprado por Antonio Miguel Méndez Pozo, pasando a incorporarse al Grupo PROMECAL (Promotora de Medios de Comunicación de Castilla y León) que él mismo había puesto en marcha en el 2000, con la idea de instalar un gran grupo de comunicación en Castilla y León y que posteriormente conoció su ampliación a Castilla la Mancha y Navarra. Al poco tiempo, "La luz de una candela”, nombre de la columna de Jiménez Lozano, se extendió a los 14 periódicos regionales de este grupo de comunicación.

\section{Síntomas de deterioro de la vida política en España}

Los artículos de Jiménez Lozano se inscriben en el contexto de la España democrática. Solo en muy contadas ocasiones hace referencia a la vida política. En los dos años que hemos estudiado, solo lo hace nueve veces. Ello indica ya la escasa importancia que da a este tipo de asuntos.

A la hora en la que otros celebraban los treinta años del fin del Régimen franquista y la posterior firma de la Carta Magna, él no se muestra tan optimista. Encuentra que la vida política corre a la deriva. A su juicio no solamente no ha alcanzado todavía su fase adulta, sino que se halla afectada de graves enfermedades que pueden conducirla a la autodestrucción. Tal como hemos adelantado, sus palabras no se ciernen a criticar las malas actuaciones del gobierno de turno, sino que van más allá de la vida política. De la mano del prestigioso periodista italiano Indro Montanelli recuerda cómo los regímenes democráticos de la Europa de principios del siglo XX se destruyeron por los errores y debilidades que tenían dentro: "la manipulación, la burla del derecho y la dimisión de la autoridad del Estado.” (Jiménez Lozano, 2007g). Por ello, porque sus palabras no tratan de criticar a una actuación puntual del Estado español, su discurso se remonta lejos en la historia, al momento de la caída del Imperio Romano. Recuerda, apoyándose en los estudios de la historiadora inglesa Eileen Power, cómo sus ciudadanos no se dieron cuenta del peligro que se cernía sobre ellos. Habían ahogado el orgullo de lo que habían sido capaces de hacer, con el confort de sus avances tecnológicos -sus sólidas carreteras y los apreciados baños-y no percibieron que la barbarie estaba a sus puertas. Algo similar estaba ocurriendo, a su juicio, en España.

"Y claro está que las carreteras -ahora infraestructuras- mejoran, a medida que las cualidades de nuestros estadistas empeoran; y los sistemas de calefacción se sutilizan; y nuestra educación está dedicada a desmontar las ruedecillas de esa nuestra propia vieja cultura" (Jiménez Lozano, 2007f).

Durante algún tiempo se publicaban en el suplemento semanal Osaca, iniciado por Promecal, pero después volvió a hacerlo en cada periódico del grupo, que son: La Tribuna de Albacete, Diario de Ávila, Diario de Burgos, Diario Palentino, La Tribuna de Ciudad Real, La Tribuna de Cuenca, La Tribuna de Guadalajara, La Tribuna de Puertollano, La Tribuna de Talavera, La Tribuna de Toledo, Diario de Miranda, La Estafeta de Navarra, El Adelantado de Segoiva, El Día de Valladolid. 
A su juicio los políticos no aprenden de la historia. Quienes se dedican a dirigir la vida pública trastocan el sentido de su tarea, sustituyendo la búsqueda del bien común por los asuntos propios. Se percibe en el lenguaje que utilizan:

“[...] la gramática con la que esos poderes discuten cuando se acuchillan con sus rivales [...] Se hacen incluso acusaciones de latrocinio y asesinato, y otras realmente impronunciables fuera del mundo del hampa y de la delincuencia en otras épocas de mayor civilidad, pero que ahora se ha convertido en lenguaje público y político normal.

[...] toda esa gramática no significa nada en la vida pública; lo que obliga a concluir que así se hace consideración del hombre público que así habla impunemente como de alguien de responsabilidad intelectual y moral nulas o muy disminuidas, porque ha prescindido de la civilidad necesaria" (Jiménez Lozano, 2007j).

De ellos emana la educación que lleva a que el país reniegue de sí mismo y se entregue a la imposición del progreso meramente tecnológico, sin dejar espacio para el pensamiento:

"Y el hombre hispánico, en particular, parece cansado y harto de que España sea España y siente hacia ella indiferencia y hasta inquina. [...] Así va extendiendo la alfombra roja de recibimiento a quienes serán nuestros señores, y de quienes seremos sus esclavos. Y parece que nos gusta" (Jiménez Lozano, 2007f).

Esa situación de la sociedad la explica por el bajo concepto que tiene de los políticos. Pone en relación de proporción inversa a los avances tecnológicos con las capacidades que ellos tienen para desarrollar su tarea. No es su intención la de criticar a los que ejercen el oficio en ese momento. De nuevo su propuesta es de fondo. Para ello se sirve de la autoridad de Sócrates. Él ya había detectado que uno de los problemas que aquejaba a la vida política era su falta de preparación profesional. Hacía caer en la cuenta que, si bien todo aquel que quería desempeñar un oficio comenzaba por aprenderlo antes de ejercerlo, no ocurría lo mismo con el de la política, para el que no se requería ni se exigía ningún aprendizaje, como si todo hombre valiera para ello. De Sócrates pasa la palabra al escritor griego Aristófanes que, en la obra de teatro de Los caballeros expresa de manera gráfica y divertida en qué consisten las cualidades para dirigir la cosa pública:

“[...] en vista de los saberes y las habilidades que mostraban de ordinario quienes conducían el carro de la cosa pública, no cabía duda de que el mejor candidato para ese puesto de auriga sería un salchichero ignorante, con tal de que, siendo ducho en su oficio, supiese entripar la casquería y los deshechos y de venderlos luego como longaniza de primera calidad" (Jiménez Lozano, 2007h).

A las reflexiones de los clásicos añade una muy personal. Asegura que los políticos piensan en su tarea en términos "teológicos", es decir, como si en ella pudiera basarse la esperanza de salvación del hombre. Eso 
era algo contra lo que había reaccionado durante los primeros pasos democráticos, en la Transición, cuando hablaba de la relatividad y caducidad de la política. Ahora lo vuelve a expresar de manera metafórica, pidiendo a los políticos que no sobredimensionen su tarea:

"Y en esas estamos; así que lo que querría el hombre del común, cuando reflexiona un poco, es que no hubiera que subirse necesariamente en el carro público; o, por lo menos, que los viajes sean cortitos y así se van probando aurigas" (Jiménez Lozano, 2007h).

Síntomas de esa tendencia al mesianismo político es el intento de encarrilar la historia, algo que a su juicio se hace a través del inflamiento del debate sobre las nacionalidades. Con el título de "España reordenada" lanza una pulla:

"Sólo así se puede entender que, entre nosotros, sea tan deportivo poner en cuestión todo y que haya gentes que como demiurgos, poseídos de hybris, traten de lo que haya sido o no haya sido, y a la inversa o de que pueda reinventarse España de otro modo y a la carta, y España no sale de radiografías, escáneres, análisis y test o experimentos, en vista de la decisión de que se trata de un enfermo imaginario que no sabría quien es, y que no debe ser lo que es" (Jiménez Lozano, 2006e).

Es patente que no apoya esa agudización de la diferencia que lleva a ciertos territorios a erigirse en repúblicas independientes. Por ello esta vez sí que critica una decisión política concreta: la decisión de que cada Autonomía programe la enseñanza de la Historia, pudiéndose prescindir de períodos como el de los Reyes Católicos u otros, a conveniencia de cada territorio.

"Hay dos principales razones: esa conciencia del poder; y desde luego, que la ignorancia de más de dos dedos de gruesa, como lo era la cristiandad de Sancho según él mismo confiesa, se ha constituido ya en situación general básica, y en signo de pertenencia a la casta limpia de la modernidad rampante, sin roce de toda tiniebla y antigualla" (Jiménez Lozano, 2005c).

Pero, por encima de su opinión, se alza el trascendental asunto del concepto y del ser de la nación, un problema cultural fundamental, básico para la convivencia. Habla de política desde su significación más amplia pues, si ésta no funciona, la sociedad se quebranta y ello puede acarrear grandes males. Se hace necesario frenar la disgregación a la que lleva el desconocimiento del ente común, que es España. Por su tendencia a ver antes la cultura que la política o por el afán de echar balones fuera, achaca el problema a la incultura reinante. Lo hace recurriendo a modos ingenuos, con la coincidencia de una fecha de resonancia infantil, en un artículo que tituló “El regalo de los Reyes Magos”. El bajo nivel al que se está llegando, hace que haya gente que no entiende a quiénes representan esos señores que aparecen vestidos pomposamente en las cabalgatas organizadas cada víspera del seis de enero y que se encuentran retratados en 
infinitud de pinturas y de esculturas, arrodillados en un establo delante de un niño. Lo mismo ocurre con el ser de España:

"Y así, podríamos descubrir que España ya está hecha desde hace unos quinientos años por lo menos, incluso no a gusto de todos porque los padres no se eligen, pero tampoco se reniegan [...]” (Jiménez Lozano, 2007a).

En el modo de tratar el tejemaneje sobre los nacionalismos se refleja la postura de un pensador más que la de un periodista. No se identifica con el papel que se le reserva a este, por más que escriba durante toda su vida en publicaciones periódicas. Más que el hecho o la noticia en sí -las discusiones sobre los nacionalismos, negociaciones, declaraciones de políticos, etc.- lo suyo es la entidad de las cosas, como explica con la imagen de las diferentes recetas que la sociedad contemporánea inventa para el gazpacho:

"Pero ya no estamos en la cultura de las esencias, en la que las cosas eran lo que eran, sino en las denominaciones, en la que las cosas son lo que se decide que sean y deben llamarse. Y entonces, gazpacho puede ser cualquier cosa, como cualquier cosa puede ser gazpacho, clara está. Nuestro sentido crítico de hombres cultos y de progreso, avezados ya al gazpacho mental del que nos nutrimos cada día, se ha hecho muy tolerante y ya aguanta todo" (Jiménez Lozano, 2006f).

En pocas ocasiones hace referencia a asuntos más circunstanciales pero, cuando lo hace, no ejerce el derecho a ofrecer su opinión política, sino que se acerca a ellos con esa luz de la candela que, como explicó en la primera entrega periodística a Promecal, quiere que guíe su escritura. Uno de ellos fue el controvertido traslado a Cataluña, de los documentos catalanes que se encuentran en el Archivo General de la Guerra Civil de Salamanca. Cuando entró a valorarlo, su opinión coincidió con la que habían defendido los partidos de la derecha, que se opusieron ferozmente a la decisión tomada por el Gobierno socialista. Se trata de una toma de posición que no es habitual en él, que se muestra exquisito para mantenerse independiente del día a día de los partidos. Sin embargo, su argumentación deja claramente especificada la ausencia de significación política de sus palabras. Es más, defendía que tal tipo de decisiones deberían ser tomadas no desde el ámbito político, sino por quienes poseyeran una competencia que les viniese por su experiencia profesional, es decir, por cuestiones técnicas. En ese texto muestra cómo, más allá de la contingencia de la noticia del momento, sus palabras proponen reflexiones más elevadas, en este caso la separación entre el poder legislativo y el ejecutivo.

"Y entonces se recuerda que el día en que comenzó a decirse con razón que "allá van leyes do quieran reyes" -es decir el desgarro de la política de toda fundamentación racional y moral. [...] El asunto no es racionalizable, se mire por donde ser mire, porque el caso es, además, que en la naturaleza misma de la democracia está la neutralidad política de la administración del Estado" (Jiménez Lozano, 2006b). 
Del mismo modo, cuando critica la decisión del Gobierno socialista de introducir la asignatura de Educación a la Ciudadanía, sus razonamientos no parecen tener que ver con ningún tipo de ideología o adscripción política. Echa mano, de nuevo, de la historia reciente de Europa, que ha conocido dos regímenes totalitarios de tendencias opuestas, pero con el común denominador de pretender la invasión de las mentes de los ciudadanos:

“[...] una asignatura de la educación a la ciudadanía y desde la más tierna edad, como se hace en los Estados totalitarios para la cría de balillas o jóvenes revolucionarios. [...] Pero, ¿de verdad que se tendría la absurda pretensión de enseñar tolerancia a los niños? Porque la tolerancia no se enseña, es algo que va de suyo, pero sólo cuando se sabe reconocer a la persona" (Jiménez Lozano, 2006c).

Asimila pues la nueva asignatura con adoctrinamiento. Detrás de esta reflexión se encuentra el convencimiento de la imperiosa necesidad de separación entre dos ámbitos de actuación: la del Estado y la del individuo. Por ello alude a la educación de la persona, en este caso en tolerancia, como algo que pertenece a otro ámbito que pasamos a estudiar a continuación.

Con los textos expuestos en estos epígrafes se muestra la relación de Jiménez Lozano con la política. Intenta no mezclarse en los fregados diarios, ni en las luchas intestinas entre los partidos. Lo que busca la luz de su candela es iluminarla para descubrir lo que se encuentra en el fondo de ella. Critica de manera fuerte a los políticos. En primer lugar por la falta de preparación profesional que se exige a quienes se van a dedicar a la tarea pública. En segundo, por su poco interés por la cultura, en concreto por la historia, que lleva a no aprender de los errores del pasado. En tercer lugar, por el desvío de su función, trocando el interés debido a lo público por el provecho personal. En cuarto, por la vanidad con la que ejercen su función, como si de ellos se esperase la solución a todos los problemas de los hombres. Y por ello critica su afán de desbordar sus límites e invadir la esfera que compete a las personas individuales. En relación con estas consideraciones se engarzan otras que constituyen el núcleo de su pensamiento y que hacen referencia a la persona y a la sociedad, que pasamos a exponer a continuación.

\section{Alarma sobre el aplastamiento sufrido por la persona y la deshumanización de la sociedad}

Otros asuntos de calado más cultural y social aparecen en las publicaciones de nuestro autor en la prensa regional de estos años. Vamos a ver cómo escribe de ellos e intentaremos demostrar que también en estos temas, junto a la crítica concreta por ciertos asuntos, se alza de manera patente la reflexión más profunda. Eso ocurría con el botellón y la movida. Inicia su artículo dejando atisbar un rastro de modernidad en sus fuentes de información, comenta la información del blog de una amiga, Julia Escobar, escritora y especia- 
lista en literatura, en el que se hace eco de los fastos que el Ayuntamiento de Madrid preparaba para celebrar los veinticinco años del pistoletazo de salida del conocido fenómeno de la movida madrileña:

\begin{abstract}
"Este año hace veinticinco que el alcalde Tierno Galván, de ingrata memoria, decretó mediante bando municipal que todos tenían que colocarse; los adolescentes de la época le obedecieron tan al pie de la letra, que muchos no llegaron a los treinta. A ver quién indemniza a sus familias ahora. [...] fue también la época en la que los jóvenes empezaron a pasar la noche fuera de casa, en contra de nuestros deseos, pero con permiso de la municipalidad, lo que, de golpe, pulverizó para siempre la ingrata, aunque necesaria autoridad paterna, al menos en materia de regulación horaria" (Jiménez Lozano, 2006g).
\end{abstract}

La crítica a los políticos que mostrábamos en el epígrafe anterior conecta aquí con la denuncia de ciertas actuaciones sociales suyas. El desvelo que por un lado manifiestan por formar a ciudadanos responsables -con la nueva asignatura de Educación a la Ciudadanía a la que nos hemos referido-, no parece en armonía con la aceptación de costumbres como la de "el botellón"-encuentros juveniles organizados en la calle con el objetivo de beber alcohol en masa-. De aquellos polvos, esos lodos. De la movida, el botellón. De los escritos de Jiménez Lozano se desprende la acusación de la falla que se abre en ciertas decisiones de las autoridades, que podrían juzgarse de esquizofrénicas, hipócritas o como mínimo, incoherentes.

Sus palabras chocan con el status quo de la cuestión. Parece que no le importa mostrarse como reaccionario ya que, tras los nuevos modos de diversión que se aprobaron como muestra de modernidad de España, está la dignidad y la vida humana. En no pocas ocasiones significó la muerte de jóvenes, pues espoleó el aumento de consumo de drogas y el alcoholismo, lo que se tradujo en accidentes de coche, en embarazos de menores de edad, en abortos.

“[...] han segado vidas en la flor de la edad, han producido traumas cuyo desarrollo continúa, y han llenado de lágrimas y luto muchas familias. Y no se puede pedir cuenta a nadie, porque ha sido asunto de todos nosotros, realmente. Aunque con diverso grado de responsabilidad y culpabilidad” (Jiménez Lozano, 2006g).

Aquel modo de divertirse supuso además un mal añadido que afectaba a cuestiones más profundas, pues abrían las compuertas a un nuevo modo de relación en la familia. La movida había llevado a despreciar la autoridad paterna y a la ruptura con el tesoro que constituía la educación que los padres les transmitían. Una auténtica revolución en la que se trastocaron los valores y se asentó el hedonismo como guía fundamenta del comportamiento,

“[...] la conformación de los esquemas mentales y éticos para esos jóvenes en la irresponsabilidad, el hedonismo, la alegre voluntad de liquidar los valores intelectuales y morales del pasado: es decir, el asesinato simbólico de 
los padres y del tiempo de los padres y presentando toda esta filosofía como un tal hallazgo de la Modernidad que el Renacimiento y el Siglo de las Luces, todo junto, resultaban una tontería" (Jiménez Lozano, 2006g).

Una vez más vemos cómo los artículos de Jiménez Lozano van más allá de la crítica periodística, que por naturaleza tiende a limitarse al momento concreto. Las referencias a la Modernidad, el Renacimiento y el Siglo de Luces están hablando del pensamiento sólido en el que se sustentan sus palabras. Despiertan intereses culturales.

A pesar de acusar a las autoridades políticas por tamaño despropósito, el de haber fomentado y después permitido el botellón, no exime de culpa al ciudadano, pues tiene claro que la intromisión de los poderes no anula la libertad en la decisión de cada uno. En este sentido vuelve a repetirse la advertencia que Jiménez Lozano realizaba en el inicio de sus colaboraciones periodísticas: iba a acercar la luz de la candela para contemplar las cosas tal cual habían sido hechas,

"Pero estas cosas no quieren saberse, ni siquiera, a veces, por aquellos a quienes aquella comedia afectó dramáticamente en su propia carne. Quizás todos nosotros preferimos no mirar, para que la fiesta continúe, sin pensar hacia dónde vamos y que la ópera bufa a la que hemos asistido hizo muertos de verdad" (Jiménez Lozano, 2006g).

En otro artículo que titula "Asunto de civilidad" trata el mismo tema desde otro punto de vista, el del respeto y el decoro:

"Un alcalde pedáneo de no hace tantos años sacaría de sus curiosas perplejidades a sociólogos, psicólogos y autoridades y padres de familia, ante las juveniles reuniones del botellón. Las prohibiría sencillamente por respeto al ágora o plaza pública que es de todos, y buen nombre del pueblo. O las ocultaría, como los hijos de Noé ocultaron la embriaguez de su padre, por respeto a la persona” (Jiménez Lozano, 2006d).

Propone la importancia de las buenas maneras. Asegura que, lejos de ser una manera hipócritas de comportarse, la educación dulcifica al animal que todos llevamos dentro:

"El respeto propio y ajeno es una delicadísima realidad que a la civilización y a la civilidad, ha costado siglos y trabajos ímprobos producir y que ha estado muchas veces, y sigue estando, en trance de perecer, por la sencilla razón de las laceraciones y golpes recibidos, o a cuenta de la irrisión y la befa con que los bárbaros siempre la han rodeado. En el plano social y público, la cortesía ha sido el gran hallazgo civilizado en que, mediante los signos del vestido, las palabras y los gestos, preservamos nuestro yo en su señorío y su fragilidad y hacemos lo mismo con el yo de los demás. Y es cuestión de formas, desde luego; pero si éstas se descomponen aparecemos los hombres inmediatamente en nuestra brutalidad neandertalense" (Jiménez Lozano, 2006d). 
El texto que acabamos de reproducir está señalando la certeza de la hipótesis inicial: José Jiménez Lozano hace propuestas de carácter universal que tienen que ver con la dignidad de la persona. El modo tan sui generis de tratar los temas candentes, con vueltas y revueltas está en relación directa con una mente que no se detiene en la contingencia de las cosas y que se pasea sin esfuerzos entre las experiencias que los hombres han tenido en la historia.

Entre los asuntos que más le preocupan y en los que se expresa con nitidez meridiana, tienen que ver con el respeto a la vida humana. No se anda con rodeos y apunta a la diana, aunque esto suponga herir las sensibilidades forjadas en la horma del pensamiento imperante. Lo hace sin ambages cuando trata sobre el aborto:

“[...] familiarizados como estamos con la arbitraria eliminación de fetos humanos. Porque ello no es más que un recuelo de la barbarie misma de los grandes totalitarismos del siglo XX, pero ha sido vertido en fórmulas de alta cultura, progreso y libertad. Todo el problema que suscita ya la vida humana queda así reducido a las cuestiones generales de granja, relativas a la reproducción, recría, estabulación, engorde y muerte" (Jiménez Lozano, 2006k).

Se expresa con duros términos, pero no agrede o descalifica a las personas implicadas, sino que descubre la relación de la mentalidad que está penetrando, con la ideología totalitaria que ha sufrido Europa en el siglo XX. Se trata de una concepción del hombre muy cercana a la de mero animal.

“[...] y , una vez más, repetición de otras noticias sobre oscuridades de ciertas clínicas de todo tipo que han horrorizado más fuera que dentro del país; o la venta sistemática de cadáveres de personas fusiladas en China, vendidos en Occidente en creciente demanda, para el trasplante de órganos humanos y otros usos. Estamos ante el horror mismo de la Science in Behemoth, o Ciencia de la Bestia bíblica, símbolo del mal, según la fórmula empleada para señalar los estudios, experimentos humanitarios y negocios con material humano, que fueron juzgados y castigados en Nuremberg” (Jiménez Lozano, 2007c).

No acepta que se presente como una ley necesaria y adecuada a una sociedad evolucionada. Está muy lejos de verlo como un "avance social” y lo explica remontándose a la historia:

"La historia va hacia su plenitud, desnichando tabúes; y si podríamos decir, pongamos por caso que el tabú del sexo de la época victoriana dejó de serlo para convertirse en mera patología infantil, es preciso acabar también con el tabú de la muerte, que individualmente no tendría importancia alguna, pero es un bien social" (Jiménez Lozano, 2006k).

Comprobamos cómo no entra en el debate sobre las distintas leyes de despenalización, sino que, una vez más, bucea en la actualidad y busca las conexiones culturales e ideológicas que pueda tener, en este caso, la costumbre social de admitir el aborto. 
En cualquier manifestación contra la vida, lo que a él le urge subrayar es que se está despreciando el concepto de hombre, a través de borrarle la conciencia de su yo, la capacidad de decidir:

"Los hombres estamos reintegrados a la historia natural, y el individuo hombre tiene la única razón de ser y de vivir en su utilidad material para la especie o el grupo social al que pertenece. Sencillamente, ya no es una persona, y sobre todos nosotros se decide, ya ahora mismo, nuestras vidas: nacimiento o no, y si nacimiento, sexo, tipo y figura, muerte dulce o eutanasia, alimentación, reproducción o no, trabajo y descanso, espectáculos e ignorancia general, básica y rentable, y según vamos admitiendo esto, vamos modernizándonos [...]” (Jiménez Lozano, 2007c).

En sus escritos menciona algunas veces la experiencia del filósofo judío, Emmanuel Levinas, en un campo de concentración nazi. Él contaba lo terrible de aquella experiencia en la que eran tratados como meros desechos. Solo un perro que por allí vagabundeaba, les reconocía como personas. Aquella ideología tan denostada, no es sin embargo lejana a la que, con buenos modales, se impone en la sociedad actual. Se trata de la liquidación del concepto hombre, al que reducen a un mero consumidor.

"Lo que hay verdaderamente nuevo en ese mundo nuestro es demasiado serio: una técnica y una burocracia más perfectas y la decisión de liquidar la fábula antropológica -todo otro concepto del hombre que no sea estrictamente biológico sería esa fábula-y la introducción de la muerte racionalizada en la idea de progreso, que ya se convirtió no hace tanto en la práctica política del Estado-Granja y en el ideal del Holocausto, y están en la misma longitud de onda cultural que nuestra cultura de ahora mismo" (Jiménez Lozano, 2007m).

Le apena comprobar que el hombre sigue siendo el peor enemigo para el hombre y ahora porque se le estaba privando de la capacidad de ser él mismo. Para reflejar la importancia de este asunto recurre, en cierta ocasión, a contar un chascarrillo del pasado,

"En otro tiempo, por ejemplo, una mocita de pueblo, encaprichada por una rebeca o unos zapatos que había visto en un escaparate en la capital, renunciaba a ellos inmediatamente si otra mocita había tenido el mismo gusto y se había adelantado en adquirir aquellos caprichos. Es decir, que asomaba ahí, en esa mocita una personalidad propia, un yo" (Jiménez Lozano, 20061).

Con tan sencillo ejemplo ejemplifica esa necesidad que las personas tienen de ser tratadas como únicas, pues así han sido hechas. Una vez más, el tamiz de su mirada no es periodística, sino del pensador que criba los sucesos de la sociedad por la reflexión y ofrece propuestas universales. Estas pasan por una crítica clara a la imposición de un pensamiento deshumanizado:

"Sencillamente porque lo que constituye el quid de una inteligencia libre está, desde luego, en que no admite andaderas del común para pensar, y no echa mano de los tarros de botica de los estereotipos o pastillitas del pensar 
propuestos por la industria cultural del tiempo. Aunque esté muy desarrollada, sea muy poderosa, y amenace con terribles estigmas si no se la obedece, como ocurre ahora mismo.

[...] La espontaneidad se ha invertido, y ahora los gustos y caprichos son sociales, comunitarios, y hasta para vestir y calzar no debe ni ocurrírsenos algo personal. Ni tampoco debemos cometer la excentricidad de saludar con unos buenos días en un autobús. Si se hace es como si los allí estantes vieran la aparición de un difunto porque la cortesía es una antigualla" (Jiménez Lozano, 2006l).

Las personas ya no son valoradas más que por la utilidad que pueda rendirle al colectivo.

"En realidad, se ha abolido la Historia y por lo tanto, el cuidado y la preocupación por la disolución de lo humano en ella, y ya puede ser disuelta ante nuestro mismos ojos como un solube-coffee, siempre de que lleve la etiqueta de modernidad, que es la garantía o denominación de origen que nos importa, porque es la que se os ha impuesto, y ya hemos probado los dulzores de la esclavitud" (Jiménez Lozano, 2007q).

En todos los artículos en los que trata de esta materia, la hipótesis que planteamos al inicio también se cumple. Jiménez Lozano no se detiene a decir lo que hay que hacer y lo que no hay que hacer. Levanta los temas, para enseñar la raíz y que cada uno actúe en consecuencia.

Para terminar este epígrafe queremos traer aquí un asunto que puede parecer trivial y que, ciertamente, al lado de los anteriores es esencialmente de menor importancia. Pero según la mirada de Jiménez Lozano, la cosa toma otro cariz y muestra dimensiones insospechadas. Se trata de lo que él denomina la pérdida de sentido de las fiestas y de los símbolos que estas necesitan para expresarse. A él se le antoja como un síntoma de la deshumanización de la sociedad contemporánea, ya que la fiesta se ha desvirtuado con el exceso de consumismo. Él, que desde siempre ha vivido en un pueblo, conoce bien todas esas cosas. Recuerda cómo en las celebraciones se encendían antorchas para alumbrar durante los cortejos. Con ocasión de las fiestas el árbol de Navidad se convertía en una maravilla para los ojos y en símbolo de júbilo. El problema se encuentra, ahora, en su degeneración por hipertrofia,

"La luz se convierte en decorado de verbena interminable que concluye con el hastío, o en la mayor indiferencia” (Jiménez Lozano, 2006m).

El exceso de luces artificiales es para él la imagen del cambio que se ha producido en la sociedad. El árbol no invita ya a la alegría de lo que ocurre en Navidad, en ese contento que tiene sus ecos en los "adentros", como le gusta decir. Las luces navideñas son ahora el reclamo del consumo. Y eso es precisamente lo que él denuncia, Este es el comportamiento más importante que se espera del hombre: 
"Pero lo que pasa es que luces y ruido son excitantes de asentimientos unánimes, y se supone que todo está muy bien estudiado para provocar como un acto reflejo en las gentes, compras y también autosatisfacciones. Exactamente como ocurre con los ratoncillos de laboratorio" (Jiménez Lozano, 2006m).

En la década de los sesenta y setenta, cuando se acercaban las fechas de Navidad y de fin de año, Jiménez Lozano, que tenía entonces treinta o cuarenta años, criticaba la manera tan mediocre e hipócrita con que se vivía una fiesta que era esencialmente religiosa. Treinta años después, las mismas fechas le inspiraban la crítica. En la misma onda, pero subrayando ahora la pérdida de sentido y la deshumanización de las costumbres, por medio de la complicación y el consumo que se ha generado en torno a ellas:

"Aunque luego, las cosas se estropearon lo suyo, y luego se han complicado, barroquizado, sofisticado, tecnologizado y culturizado, que es un horror. [...] Y periódicos y revistas , y los otros media, ofrecen cada año nuevas y muy alambicadas recetas para la cena de Nochebuena, o las Fiestas del Solsticio Invernal, según el ya viejo, y bastante imbécil, calendario laicista que se nos propone" (Jiménez Lozano, 2006n).

Se podría decir que con el tiempo, José Jiménez Lozano se muestra cada vez más escéptico, más crítico, más preocupado por la deriva cultural del mundo en el que vive. Con la llegada del otoño, este sentimiento se agudiza. Antaño era tiempo fecundo en tradiciones, bien aromatizado con el olor de un fruto tardío, el membrillo, que impregnaba toda una cultura popular:

"Pero ya nada debe conservarse, y todo es de mero uso accidental, o más bien ya nada hay que conservar porque todo es nada y no significa nada. Y si el otoño y los membrillos eran antes un asunto de melancolía, ahora ya no lo son. El otoño tiene su celebración en los grandes almacenes y en los tenderetes políticos con promociones de nuevas mercancías igualmente y el rojo y el oro con los que la naturaleza se prepara para la devastación del invierno son sólo masa de colores, como se dice de las pinturas. [...] Todo nos resbala amablemente y nada nos atañe; y, entonces, todo deja de ser lo que es, si no tiene su eco en nosotros, Pero también nosotros dejamos de ser nosotros, tampoco significamos nada" (Jiménez Lozano, 2006i).

En definitiva, a través de la actualidad más liviana o de asuntos de calado, el mensaje que recorre los textos del autor en la prensa regional durante los años 2005-2007, se condensa en una alarma continua sobre la deshumanización de la sociedad y el aplastamiento de la persona.

\section{Vehículos de deshumanización}

José Jiménez Lozano señala varios vehículos por los que se estaba conduciendo a esa homogeneización del pensamiento, de los sentimientos y a ese vaciamiento del sentido de lo humano. Nos hacemos eco de tres: la escuela, los medios de comunicación y el empleo de un lenguaje empobrecedor. 
En un artículo titulado "Enseñanza de baja intensidad" se detiene a mostrar su rechazo a un nuevo tipo de educación que pretende homogenizar a todos a base de rebajar sus contenidos y minimizar las exigencias.

"Las nefastas consecuencias de los ensayos ideológicos y pedagógicos de todos estos últimos años han bajado el nivel cultural y educativo hasta un punto ciertamente escandaloso y tristísimo. Y han dado lugar a situaciones entre trágicas y grotescas en las que, pongamos por caso, si un alumno no aprueba según sus posibilidades, la ley se las regalas, para evitar el terrible trauma del suspenso" (Jiménez Lozano, 2005b).

Se dictaron nuevas leyes que proponían la supresión de los exámenes finales. La medida le parecía fuera de sentido y además un engaño para los estudiantes, a los que so capa de hacerles un favor, se les hace enanitos. Por eso lo compara con lo que suele hacerse con ciertos juegos infantiles:

"La cosa funciona a ese ras de conocimientos, para todos al nivel de los menos dotados o de los que no quieren trabajar, como con el juego de la comba de un niñito de dos años que se empeña en jugar a ella. Se le pone la soga bajita para que se haga la ilusión de que él también salta, y en paz" (Jiménez Lozano, 2005b).

Además de la acertada comparación, el asunto iba más lejos pues tenía unos precedentes en el sistema totalitario comunista de Mao. En aquella ideología, los exámenes se consideraban como un método reaccionario, burgués, que no se acordaba con los presupuestos revolucionarios, por lo que había que deshacerse de ellos. Las consecuencias estaban a la vista:

"En la China del señor Mao, desde luego, gentes perfectamente analfabetas enseñaban historia o medicina, y hasta hacían intervenciones quirúrgicas a su manera, con la única guía de los pensamientos y poemas del presidente Mao [...]” (Jiménez Lozano, 2005b).

“¿Qué harán esos jovencitos, si un día se percatan a su costa del cuento chino que han vivido sin saberlo?” (Jiménez Lozano, 2007d).

Ligado a la escuela, cita el desprecio que existe en el conocimiento de la historia, en particular de España.

“[...] las nuevas generaciones de españolitos, aunque por aquí no ha estado el señor Mao, no tiene mayor idea de lo que han sido España y el mundo, pero por ley quedan dispensados de ello” (Jiménez Lozano, 2007d).

Detrás de esa ignorancia inculcada, también acusaba a la manía española de despreciar su propia cultura e historia.

"El odio acumulado contra la cultura española, que es muy sectario y suicida, ha llamado siempre la atención del mundo. Es el odio a los padres y a todo lo que nos ha precedido, o el imbécil adanismo de quienes piensan que están reinventando la realidad. Y es un odio inútil [...] Aunque la barbarie siempre deja sus huellas de necedad y maldad, verdaderamente irreparables" (Jiménez Lozano, 2007d). 
Con la facilidad con la que nuestro autor pasa de un asunto a otros, de uno serio lo deriva a lo liviano y al contrario, resulta sorprendente cómo el tema de la memoria de la historia lo liga al sucederse de las estaciones. Así lo aplica a los comentarios que se hacen sobre las nevadas en el mes de enero o febrero.

"Es tal el desprecio nuestro a la historia, y a la vida de los que fueron, lo que hace que los media, por ejemplo, nos los presenten ahora como acontecimientos singulares, extraños y anormales. ¿Es tan intenso nuestro complejo adámico de gentes que están inaugurando el mundo que nos parece que en el que pensamos levantar no habrá lugar para esos acontecimientos adversos?" (Jiménez Lozano, 2007o).

Otro síntoma que él detecta de la peligrosa deriva por la que va la sociedad es la manipulación y la vaciedad del lenguaje. Lo explica, por ejemplo, en relación con todo lo que se ha denominado lenguaje no sexista. A pesar de ser un modo de decir que se impone como lo aceptable en ese momento, él reacciona en contra. De nuevo, no con el afán político, de posicionarse como conservador o progresista, sino por la vaciedad que encuentra en esta expresión: las palabras no tienen sexo,

“Tienen género, y al igual que la mujer no es un género, sino una persona, una palabra no es una mujer, y tampoco una cabra o una pluma. Y si yo digo palabro he dicho algo que no significa los mismo que palabra; e igual ocurre si digo 'culebro' en vez de 'culebra', o si digo 'grados' nombro otra cosa que si digo 'gradas', lo que indica que hay aquí algo que no son variaciones de género, sino significantes de realidades distintas” (Jiménez Lozano, 2007h).

Al hablar de "violencia de género", según su modo de entender, se edulcora la terrible realidad: se trata de asesinatos de mujeres. Las noticias de la prensa reiteran el término en las noticias correspondientes. Él tacha de barbarie los asesinatos de mujeres, pero, una vez más, se sitúa en un plano más filosófico y denuncia la mentalidad de toda una sociedad que borra el rostro de lo humano hasta en el lenguaje, llamando violencia doméstica al asesinato.

"Y es aquí donde están los riesgos de una lengua: en que su gramática comience por ser idiota, llamando, por ejemplo, infraestructura a una carretera, y concluya por aceptar el asesinato, en el caso que digo o para ofrecer calidad de muerte" (Jiménez Lozano, 2006a).

Jiménez Lozano recordaba que Rousseau defendía a ultranza la bondad genuina del hombre y por ello proclamaba que no solo este no necesitaba una enseñanza, sino que lo mejor para su educación era no recibir ninguna. Esa simpleza, lo que se conoce como ingenuismo roussioniano, no se corresponde con la historia humana. No había más que asomarse a la reciente historia europea para ver la brutalidad en la que había desembocado en el siglo XX. Algunas de sus manifestaciones habían sido sangrientas. Otras no, pero no por ello dejan de ser igualmente bárbaras y continúan atravesando la sociedad, con una carga 
asesina en sus entrañas: la desconsideración por el hombre y la devaluación del lenguaje a mero ruido o a falsedades:

"Los discursos políticos son cada día más platónicos [...] La retórica de la llamada corrección política es cada vez más encantadora y, por ejemplo, el asesinato de mujeres se llama encantadoramente violencia de género. Es decir, algo tan abstracto como las representaciones artísticas, sin rostro ni figura humanas, ni escorzo de animal, planta o cosa, sino enigmas en forma de mancha y geometría. [...] no hay Mal, sino errores y violencias que sólo precisan para ser eliminados, encanto y comprensiones. Es una forma de eutanasia social encantadora" (Jiménez Lozano, 2006j).

Llega su denuncia hasta el punto de decir que lo que la sociedad valora es cambiar el sentido de las cosas, concediéndole aquel que el aire de los tiempos demande:

"Por ejemplo, por lo políticamente correcto, que es no llamar a las cosas por su nombre, y no decir una sola verdad; y por lo tanto, lo de la cuesta de enero ya será una locución demasiado fuerte y quedará obsoleta. En adelante, sólo se hablará de algo así como de curva negativamente ascendente en el ingreso doméstico, que debe asumirse con talante positivo. Y asunto concluido" (Jiménez Lozano, 2007r).

En este asunto del lenguaje, también su crítica desemboca en una propuesta cultural, en este caso una mirada a la historia. Le gustaba recordar la de la construcción de la Torre de Babel, como un buen ejemplo del intento de querer imponer un mismo pensamiento en los hombres, a través de una misma lengua.

"A comenzar por el rey Nimrod, que para eso precisamente proyectó la famosa Torre de Babel: para que los hombres todos abrieran la boca del mismo modo y tuvieran los mismos pensamientos. Y de esto se trata siempre que se inventa una gramática nueva" (Jiménez Lozano, 2006j).

"Ya el primer totalitarismo del mundo, el del rey Nimrod, que quiso alzarse hasta el cielo construyendo una torre, se asentaba en la idea de que todos debían mover los labios del mismo modo para que tuvieran los mismos pensamientos, hasta que Yahvé devolvió a cada cual su boca y sus pensares y la torre se vino abajo" (Jiménez Lozano, 2006a).

El otro vehículo poderoso de manipulación y homogenización son los medios de comunicación. Su condición de periodista no le exime de crítica a su profesión, sino al contrario. En los artículos que hemos estudiado lo hace en dos sentidos. El primero de ellos hace referencia a la esencia misma de los medios de comunicación en la sociedad contemporánea. La técnica ha facilitado la multiplicación de los mensajes. Aquello que parecía un bien para el hombre y para el buen funcionamiento de la sociedad democrática, se volvía en su contra. La multiplicidad de mensajes se traduce con facilidad en saturación y embotamiento. Le gusta hacer referencia a una imagen utilizada por uno de los primeros estudiosos de 
la comunicación en las sociedades contemporáneas, Máximo Fini: un plato de menestra es capaz de calmar el hambre de una persona, dos quizás le saciaría, tres le produciría hartura y más allá de cuatro podría matarlo. Aplicaba esa teoría a lo sucedido durante la Guerra de las Malvinas. La cantidad de informaciones hacía que las noticias al final morían por sobreabundancia y confirmaba el diagnóstico de la menestra.

"En todas las guerras o convulsiones político-sociales extremas, lo primero que han hecho todas las autoridades, militares o no, ha sido instaurar lógicamente la censura de noticias; pero ya con ocasión de la guerra de las Malvinas, el Estado Mayor británico no mostró el mínimo interés en una cosa así, por la sencilla razón de que las noticias que generó el conflicto fueron tal avalancha, que por sí solas equivalían a la desinformación más perfecta" (Jiménez Lozano, 2007i).

Al final, de tanta información sale un ruido tan fuerte que, para hacerse oír, hay que gritar más fuerte aún. Ello produce un cacareo que Jiménez Lozano expresa con la figura bíblica de la que ya hemos hecho mención, la Torre de Babel, la confusión de lenguas:

"Y por la fuerza misma de las cosas, dentro ya de esta Babel impresionante, para que algo sea impresionante y noticiable por lo tanto, tiene que ser algo mucho más babélico e impresionante, de manera que se termina noticiando o glosando cualquier cosa con tal de que sea archi-impresionante" (Jiménez Lozano, 2007i).

Además, la multiplicación de la comunicación, especialmente vía televisión, le da la impresión de que convierte a los receptores en meros consumidores de noticias, como si estas no fueran más que un producto. Contraponía su efecto al que tiene un libro, que llega a los adentros del hombre y tiene capacidad de transformarlo. Las noticias solían reducirse a la impresión que causaba en el mismo momento de su recepción,

“[...] sólo se hace como para ponernos un escalofrío en la espalda y suscitar una emoción” (Jiménez Lozano, 2007o).

El segundo sentido de su crítica guarda relación con la preponderancia y la hipervalorización que tiene la opinión en los medios de comunicación:

"Pero ahora las necedades son tecnológicas, usan coturnos y mantos relucientes, y tienen un gran empaque. Y poder. Se llaman, por ejemplo, opinión, que es una especie de mantra sagrado ante el que hay que prosternarse, porque hay otro mantra que dice que todas las opiniones son respetables".

En los oídos contemporáneos no suena bien esta última afirmación. Quizás por ello se apoya en una autoridad del porte de Sócrates para explicar lo que significa la opinión: 
"Desde Sócrates está claro que la opinión no es nada. No se puede opinar de lo que se sabe porque ya se sabe, ni de lo que no se sabe, porque no se sabe; y sólo cuando resabe algo de un asunto se hacen hipótesis u opiniones fundadas, como calas y tanteos en busca de la certeza" (Jiménez Lozano, 2007f).

Hace una llamada a la cordura para no caer en el vacío total que podría ser si la opinión reina en lugar de la verdad:

"Pero hay una categoría central de nuestra civilización que es la del pudor y éste invita por lo menos a un cierto silencio, pero también a no revestir de prestigio las necedades, repitiéndolas como categorías del pensar. Porque si las mentiras repetidas cuajan en brillante apariencia de verdad, las necedades repetidas se constituyen hasta en sistema. Y nuestro discurso público y privado se alimenta de ellas, y es puro ruido; no quiere decir nada" (Jiménez Lozano, 2007f).

Junto a la abundancia de opinión y la sustitución que hacía de la noticia, le llamaba la atención ciertas noticias que saltaban a la palestra de la actualidad, cuando en realidad eran fenómenos muy viejos y reiterativos. De nuevo le provoca esta reacción los comentarios sobre los cortes eléctricos que causó una nevada en el 2007. Los medios de comunicación se afanaban en ofrecer todo tipo de explicaciones sobre lo sucedido:

"Aunque expertos hay, desde luego, que lo explican todo, y algún día habrá una normativa homologante a la que se sometan esos extraños fenómenos invernales y sus efectos colaterales. [...] Pero quedamos tan contentos, porque es como si el tendido neuronal del sentido común fuera ya tan supersofisticado como el eléctrico, ya se ve que a su tecnología actual, altamente sensible, también le afectan lo suyo los cambios atmosféricos" (Jiménez Lozano, 2007b).

Podemos ratificar la idea de partida de este trabajo: Jiménez Lozano no se queda solo con la crítica del momento, como sería la redundancia de noticias sobre un hecho previsible, sino que saca consecuencias para el hombre, lecciones incluso de la climatología, sin darle tanta importancia a las consecuencias que tenga sobre la sociedad:

"Es decir, que esas cosas nos informaban de la fragilidad de nuestra vida y de todo lo que nos rodea y vive [...]" (Jiménez Lozano, 2007o).

Con el nombre de "Vamos a contar mentiras" citamos un último artículo que rezuma tristeza ante el panorama que ofrece la sociedad actual:

“[...] así nos encontramos ahora, con todo en ruinas. Hasta la mentira. Porque ya no hay embustes, en efecto; entre otras razones, porque ya no hay verdades. Ni hay víctimas porque no hay verdugos y no hay mal porque no hay bien" (Jiménez Lozano, 2007e). 
El título del artículo responde a la cancioncilla que cantaban en corro las niñas durante muchos años: "vamos a contar mentiras, por el mar corren las liebres, por el monte las sardinas". De tal estrofa toma pie para clavar el dardo en la diana del mal de nuestro tiempo: no hay verdad, no hay bien. Las palabras de José Jiménez Lozano no pueden dejar indiferentes y realmente se alzan como propuestas de reflexión para el hombre de hoy.

\section{Conclusión}

Hemos ido viendo cómo los artículos que José Jiménez Lozano publica en la prensa regional actual, constituyen un grito de alerta sobre la deriva de la sociedad española, la denigración de la dignidad humana y la deshumanización de la sociedad. El diagnóstico que el autor va dibujando es pesimista y duro. Anunciamos como hipótesis que sus textos traspasan la contingencia de lo periodístico para convertirse en propuestas culturales con tonalidad universal. En medio de la oscuridad que presenta, ofrece también algunos signos de esperanza. Lo hace utilizando de nuevo la metáfora en un bello artículo titulado "Los milenarios botijos", en el que sale al paso de quienes, confiados solo en el desarrollo de la técnica, desprecian lo sencillo. Quizás por su cercanía con el mundo rural, responde a una descalificación sobre "la España del botijo". Jiménez Lozano transforma el pretendido insulto en una glosa a esa denostada fragilidad de la sociedad artesanal, en la que todavía no ha hecho impacto la tecnología. Lo hace comparando aquella, representada en el botijo y esta, representada por el frigorífico. La diferencia radica en las esencias. El botijo conserva el agua fría, el frigorífico, como indica su etimología-fare frigo- la fabricaba. Eso era lo que ahora se hace con la técnica, hacer frío.

"Y sin embargo los botijos-botijos tiene una más importante historia. Hechos de la misma tierra roja que el hombre, los botijos-botijos no sólo han guardado el agua para apagar la sed [...] sino que han encarnado las más profundas imágenes del afán, la esperanza y la alegría o la tristeza y soledad de ánima de los hombres. Incluso con frecuencia han acompañado a éstos en el sepulcro, como recordación y consuelo, en lo oscuro, de lo más luminoso de sus vidas y, aún hechos añicos, han ofrecido señales, a las generaciones que vendrían, para que se conociera ese vivir y se supieran sus pensamientos. Y como tales notarios, esos añicos han sido puestos, luego, sobre terciopelos y sedas, en los museos, después de estudiarlos con eruditas catalogaciones y disquisiciones" (Jiménez Lozano, 2007l).

De manera sublime muestra aquí su propuesta cultural y humanística: la vida del hombre, por frágil que pueda ser, guarda en sí toda la dignidad del botijo, capaz de superar el paso del tiempo, de hablar de sí mismo aun estando muerto y de ser elevado en objeto de admiración de museo, aun cuando se encuentre hecho pedazos, es decir, en las minusvalías, enfermedades y fracasos de las personas. 
La candela con la que Jiménez Lozano quiere alumbrar tenuemente a la sociedad, parece que aporta poca luz. Pero ilumina un rincón desde el que se puede penetrar en el sosiego de recuperar las dimensiones de lo humano. Es la luz que emanan los libros, a cuyo encuentro animaba sin desmayo. La del juego y la fiesta como espacios de libertad del hombre y que la sociedad contemporánea pretende también devorar con su mentalidad de producción y consumo, hasta casi prostituirla cuando inventa una fórmula en sí contradictoria, las fiestas-negocio, una fiesta de diseño, como la calificó tomando el término tan traído y llevado en el mundo gastronómico (Jiménez Lozano, 2006h). En contraposición a ese nuevo engendro, reivindica la sencillez con la que comenzó a celebrarse una de las grandes e ineludibles fiestas de la humanidad: la Navidad.

"En cualquier caso, era una noche de esperanza, que siempre es una alegría muy profunda, y eso hacía que cualquier cosa en la mesa fuera un manjar" (Jiménez Lozano, 2006h).

El mensaje de esa destacada fecha lo explica con una imagen muy bella: la del rumor que se extendió sobre un niño que había nacido en un pesebre. Describe cómo las gentes sencillas de los alrededores pudieron ir a verle y alegrarse con ello, pero a la gente poderosa les dio mucho miedo:

"Y se inquietaban irremediablemente, porque nada hay que empavorezca más a un poder de este mundo que lo débil y lo frágil, el susurro, la alegría, un yo” (Jiménez Lozano, 2005d).

Frente a la prepotencia de la técnica alza así el poder de la debilidad, una manera de decir que frente a la deshumanización de la sociedad tecnológica, proponía escuchar las consecuencias que tenía aquella antigua noticia que hablaba de la dignidad de cada persona.

El lenguaje periodístico queda reemplazado por la simbología literaria. Con él, José Jiménez Lozano va entrelazando el oscuro panorama del devenir social, con luminarias de esperanza. No en vano, una de sus últimas obras literarias, Libro de Visitantes, trae a la palestra de la actualidad aquel acontecimiento que provocó el constante susurro que se transmite desde hace más de veinte siglos.

\section{Referencias bibliográficas}

Delibes, M. (1968): Vivir al día. Barcelona: Destino.

González, J. R. (ed.) (2003): José Jiménez Lozano. Valladolid: Universidad de Valladolid/Junta de Castilla y León.

Ibáñez Ibáñez, J. R. (2005): La escritura reivindicada, Claves interpretativas en los ensayos de José Jiménez Lozano. Valladolid: Junta de Castilla y León. 
Jiménez Lozano, J. (2005a): “¿Tiempo románticos?”, El Día de Valladolid, 20 de noviembre.

- (2005c): "La historia como menú”, Osaca, 4 de diciembre, p.8.

- (2005d): “Un rumor en la noche”, El Día de Valladolid, 18 de diciembre, p.3

- (2005b): “Enseñanza de baja intensidad”, Osaca, 4 de diciembre, p.8.

- (2006a): “La lengua de cada uno”, El Día de Valladolid, 15 de enero, p.3.

- (2006b): “Leyes picudas”, El Día de Valladolid, 29 de enero, p.3.

- (2006c): “Los perros y los niños”, El Día de Valladolid, 12 de marzo, p.3.

- (2006d): "Asunto de civilidad", Osaca, 26 de marzo, p.8.

- (2006e): “España reordenada”, Osaca, 7 de mayo, p.8.

- (2006f): “Gazpachos”, El Día de Valladolid, 2 de julio, p.3.

- (2006g): “Celebraciones”, El Día de Valladolid, 30 de julio, p.3.

- (2006h): “Fiestas de diseño", El Día de Valladolid, 19 de octubre, p.3.

- (2006i): “El otoño ya no hiere”, El Día de Valladolid, 29 de octubre, p.3.

- (2006j): “Encantos y comprensiones", Osaca, 5 de noviembre, p.8.

- (2006k): “La propuesta del señor Deán”, Osaca, 19 de noviembre, p.8.

- (2006l): "El queso como problema”, Osaca, 26 de noviembre, p.8.

- (2006m): “Luces y fogatas”, Osaca, 10 de diciembre, p.8.

- (2006n): “Cenas de Nochebuena”, Osaca, 24 de diciembre, p.8.

- (2007a): "El regalo de los Reyes Magos”, Osaca, 7 de enero, p.8.

- (2007b): “Sorpresas y explicaciones”, Osaca, 21 de enero, p.8.

- (2007c): “Así se amplían nuestras mentes", Osaca, 28 de enero, p.8.

- (2007d): “Un cuento chino", Osaca, 4 de febrero, p.8.

- (2007e): "Vamos a contar mentiras", Osaca, 11 de marzo, p.8.

- (2007f): “La necedad como empaque”, Osaca, 25 de marzo, p.8

- (2007g): "La helada negra”, Osaca, 22 de abril, p.8.

- (2007h): “Lección de salchichero”, Osaca, 6 de mayo, p.8. 
- (2007i): “Demasiados platos de menestras", Osaca, 20 de mayo, p.8.

- (2007j): “Civilidad y lenguajes”, Osaca, 3 de junio, p.8.

- (2007k): "Políticos e infraestructuras”, El Día de Valladolid, 17 de junio, p.3.

- (2007l): “Los milenarios botijos”, El Día de Valladolid, 5 de agosto, p.3.

- (2007m): “El termómetro chino”, El Día de Valladolid, 19 de agosto, p.3.

- (2007n): “Jergas muy peligrosas”, El Día de Valladolid, 2 de septiembre, p.3.

- (2007o): “Catástrofes naturales," Osaca, 28 de octubre, p.8.

- (2007p): “Ideas y noticias", Osaca, 25 de noviembre, p.8.

- (2007q): “Un hombre a la antigua”, El Día de Valladolid, 8 de abril, p.3.

- (2007r): "Himalayas de Enero", El Día de Valladolid, 14 de enero, p.3.

Merino Bobillo, M. (2011): Palabras que apuntan lejos. La trayectoria de José Jiménez Lozano en la prensa. Madrid: Fragua. 